\title{
Power quality analysis based on simulation and MATLAB/Simulink
}

\author{
Ahmed Salam Hussein, Majli Nema Hawas \\ Department of Electrical Power Engineering, Electrical Engineering Technical College, Middle Technical University, \\ Iraq
}

\begin{tabular}{l} 
Article Info \\
\hline Article history: \\
Received Feb 2, 2019 \\
Revised May 30, 2019 \\
Accepted Jul 19, 2019 \\
\hline
\end{tabular}

Keywords:

Matlab/Simulink

Power quality

Voltage sag

Voltage swell

\begin{abstract}
This paper in existence a complete system connected to all situations power quality event, which has been achieved using MATLAB/SIMULINK and utilizing parametric equations. In electrical energy allocation system, the disturbances of power quality have emerged as an important matter for usefulness and customers. This design incorporates distribution two capacitor bank, line fault, starting of induction motor, non-linear load and transformer energizing that are usage to simulate diverse kind of voltage sag. In simulate voltage provisional through distribution network produced as a result of effect capacitor bank switching version in the general model. For clarity, this model is advanced with an integrated block and setting in which all event situations are organized for energy quality without scarifying the gist it. This model Integrated is too beneficial to simulate different energy quality waveforms. The performance of the brand new automated categorization algorithms received are appropriate for checking waveforms of power quality.
\end{abstract}

Copyright $\odot 2019$ Institute of Advanced Engineering and Science. All rights reserved.

\section{Corresponding Author:}

Ahmed Salam Hussein,

Department of Electrical Power Engineering, Electrical Engineering Technical college,

Middle Technical University, Baghdad, Iraq.

E-mail: Ahmed.salam1000@yahoo.com

\section{INTRODUCTION}

Power quality(PQ) is an essential part of energy system building. It assumes a paramount part to guarantee the nature from claiming energy being conveyed of the industry client. Fault happen at transmission or distribution a gesture PQ event including voltage sag resulting from fault happened through transmission or distribution degree might reason the influenced industries arrive to hundreds from thousands of pecuniary casualty [1-2]. The AC power supply device is designed to perform at a sinusoidal voltage with a regular frequency (commonly 50 or $60 \mathrm{~Hz}$ ). A flicker, harmonic, transient, voltage notch, voltage swell and voltage sag these are classifications events of power quality. Power quality research is the investigation of different wonders that causes control quality occasion to happen and the improvement of extenuation strategy. The power quality disturbances are establishing each time there is a sizeable alternate in the supply voltage importance, supply frequency, and/or waveform deviation because of numerous varieties of faults, nonlinear loads, switching of heavy hundreds, strength electronics converters etc. [3-4].

The non-stop energy systems enlargement and load of varying nature have imposed high requirements in defensive equipment's, especially related with pace and accuracy. these are crucial factors for fault clearance. If a fault isn't nicely detected and eliminated, vast harm or an electricity gadget blackout can also take location. The behavior of defensive devices may trade with the diverse styles of loads including linear and non-linear hundreds related with the distribution gadget [5]. Simulation method is one of the widely used studies approach to version and simulate diverse energy first-rate events. Simulation method offers an intuition from how the PQ exceptional occasion behaves via converting the simulation parameters 
[6-7] and is beneficial for demonstrate proposal. Simulation is likewise usually accustomed for simulate energy satisfactory proceedings waveform to appraisal of energy anatomy algorithm. There is numerous energy device simulation gear [8] to be had and every simulation equipment has it very own deserve [9]. However, those widely used within the academic studies network are ATP/EMTP [10], PSCAD/EMTDC [11], MATLAB with Power System Toolbox [12-13], Power System Analysis Toolbox [14-15], Simulink with SimPowerSystems blockset [16-18]. In this paper, MATLAB/Simulink with SimPowerSystems blockset is chosen as simulation platform due to the fact it is broadly used in lots of universities round the sector and thus far there may be no propriety reporting a complete PQ occasion simulation in simulink models. This paper gift an all-round format of simulink fashions usage for simulation assorted power quality occasions.

\section{SIMULINK MODEL}

Simulink model usually incorporate distribution nonlinear load, capacitor bank switching, transformer energizing, induction motor starting and line fault string-theory are represented in the pursuing parts to simulate energy quality occurrence. The stage of distribution voltage used inside the pattern is founded on Iraq pattern code.

\section{TYPES DISTURBANCES OF POWER QUALITY}

\subsection{Voltage Sag}

The voltage sag can be known is the to the highest degree common kind of power quality disturbances that is typically lasting from 0.5 to 10 round inside the users' premises. It's commonly related with faults in the short circuit which includes line to line (LL), line to ground (LG), three phase to ground (LLLG) and double-line to ground (LLG) faults [19-20].

\subsection{Voltage Swell}

It is too related within the short track faults at energy system. The sag could be produced at the section wherein fault is happened whilst the swell is created at non-fault levels, In a (LG) fault. It's can be establishing via change-off an energizing a big capacitor bank or heavy load [19-20].

\subsection{Interruption}

The interruption is known the entire mislay to the supply voltage for a time frame no longer exceeding 1 minute. The supply of voltage could be reduced to $10 \%$ to the formal worth. The energy device faults, manage features are the consequences of the interruption and system failure [19-20].

\subsection{Harmonics}

It's currents owning frequencies or sinusoidal voltages which can be integer increases to the basic frequency $(50$ or $60 \mathrm{~Hz})$. It is specially as a result of the nonlinear loads inclusive of inverters and rectifiers and different static energy conversion system [19-20].

\subsection{Transients}

The transient is known an unwanted and brief occurrence in strength device. It's can be categorized as impulsive and oscillatory. The transient manufactured owing into switching on/off of capacitor financial institution energization, oscillatory temporary and heavy load. The temporary normally as a result of the lightning strokes is called impulsive temporary [19-20].

\subsection{Voltage Flickers}

The flickers are structured differences from the deliver voltage surround or a chain from casual voltage difference, the significance of which does now not be over via 0.9 to1.1 pu. The voltage perversions result by the non-stop and quick accounts inside the load are described as fluctuations. It is an electromagnetic occurrence whilst fluctuation is an unpleasant consequence to the voltage inconstancy in some load. each terms have equal that means in standards [19-20].

\subsection{Power Frequency Variations}

It is known the perversion inside the essential frequency of its unique titular amount $(60 \mathrm{or} 50 \mathrm{~Hz})$. There's moderate version at frequency owing as mismatch inter generation and load. The strength frequency editions are due to faults at the volume energy conveyances system, a big ban for load existence 
disconnected. The energy device frequency (f) known as is straight delay for the rotatory speed (Ns) to the concurrent generators with constant range from poles $(\mathrm{P})(\mathrm{Ns}=\mathrm{f} * 120 / \mathrm{P})$ [19-20].

Power Quality disturbances waveformsas shown in Figure 1. Disturbances of Power Quality for Mathematical Model as shown in Table 1.

Table 1. Disturbances of Power Quality for Mathematical Model

\begin{tabular}{|c|c|c|}
\hline Disturbances & Equation & Controlling Parameter \\
\hline Pure sine & $y(t)=A \sin (w t)$ & $\begin{array}{c}w=2 \pi f, \mathrm{~A}=1 \\
t=[0: 0.0001: 0.4]\end{array}$ \\
\hline Sag & $y(t)=A\left(1-\alpha\left(u\left(t-t_{1}\right)-u\left(t-t_{2}\right)\right)\right) \sin (\omega t)$ & $\begin{array}{c}0.1 \leq \alpha \geq 0.9 \\
\alpha=0.5, A=1 \\
t_{1}=0.05 \text { to } t_{2}=0.15\end{array}$ \\
\hline Swell & $y(t)=A\left(1+\alpha\left(u\left(t-t_{1}\right)-u\left(t-t_{2}\right)\right)\right) \sin (\omega t)$ & $\begin{array}{c}0.1 \leq \alpha \geq 0.9 \\
\alpha=0.5, A=1 \\
t_{1}=0.05 \text { to } t_{2}=0.15\end{array}$ \\
\hline Interruption & $y(t)=A\left(1-\alpha\left(u\left(t-t_{1}\right)-u\left(t-t_{2}\right)\right)\right) \sin (\omega t)$ & $\begin{array}{c}0.1 \leq \alpha \geq 0.9 \\
\alpha=0.95, A=1 \\
t_{1}=0.05 \text { to } t_{2}=0.15\end{array}$ \\
\hline $\begin{array}{l}\text { Oscillatory } \\
\text { Transients }\end{array}$ & $y(t)=A\left[\sin (w t)+u\left(t-t_{2}\right)-u\left(t-t_{1}\right) * e^{-t / t y} * \sin \left(\omega t * f_{n}\right)\right]$ & $\begin{array}{l}t_{1}=0.06 \text { to } t_{2}=0.058 \\
300 \leq f_{n} \geq 900 \mathrm{~Hz} \\
\text { ty }=(\mathrm{t} 1+\mathrm{t} 2) / 2\end{array}$ \\
\hline Flicker & $y(t)=A(1+\alpha(\sin (\beta * \omega t))) * \sin (\omega t)$ & $\begin{array}{c}\alpha=0.15, \beta=7.5 \\
t_{1}=0.05 \text { to } t_{2}=0.15\end{array}$ \\
\hline Harmonics & $\begin{array}{c}\alpha=\left(1-\alpha_{3}^{2}-\alpha_{5}^{2}-\alpha_{7}^{2}\right)^{2} \\
y(t)=\alpha \sin (\omega t)+\alpha_{3} \sin (3 \omega t)+\alpha_{5} \sin (5 \omega t)+\alpha_{7} \sin (7 \omega t)\end{array}$ & $\begin{array}{c}0.05 \leq \alpha_{3.5 .7} \geq 0.15 \\
\alpha_{3}=0.15 \\
\alpha_{5}=0.15 \\
\alpha_{7}=0.15 \\
t_{1}=0.0001 \text { to } t_{2}=0.4\end{array}$ \\
\hline Sag harmonics & $\begin{array}{l}\quad \alpha=\left(1-\alpha_{3}^{2}-\alpha_{5}^{2}-\alpha_{7}^{2}\right)^{2} \\
y(t)=\left(1-\alpha *\left(u\left(t-t_{1}\right)-u\left(t-t_{2}\right)\right)\right) * \alpha \sin (\omega t)+\alpha_{3} \sin (3 \omega t)+ \\
\alpha_{5} \sin (5 \omega t)\end{array}$ & $\begin{array}{c}0.05 \leq \alpha_{3.5 .7} \geq 0.15 \\
\alpha_{1}=0.5 \\
\alpha_{3}=0.15 \\
\alpha_{5}=0.15 \\
\alpha_{7}=0.15 \\
t_{1}=0.0001 \text { to } t_{2}=0.4 \\
t=[0: 0.0001: 0.4]\end{array}$ \\
\hline $\begin{array}{l}\text { Swell } \\
\text { harmonics }\end{array}$ & $\begin{array}{l}\quad \alpha=\left(1-\alpha_{3}^{2}-\alpha_{5}^{2}-\alpha_{7}^{2}\right)^{2} \\
y(t)=\left(1+\alpha *\left(u\left(t-t_{1}\right)-u\left(t-t_{2}\right)\right)\right) * \alpha \sin (\omega t)+\alpha_{3} \sin (3 \omega t)+ \\
\alpha_{5} \sin (5 \omega t)\end{array}$ & $\begin{array}{c}0.05 \leq \alpha_{3.5 .7} \geq 0.15 \\
\alpha_{1}=0.5 \\
\alpha_{3}=0.15 \\
\alpha_{5}=0.15 \\
\alpha_{7}=0.15 \\
t_{1}=0.0001 \text { to } t_{2}=0.4 \\
t=[0: 0.0001: 0.4]\end{array}$ \\
\hline
\end{tabular}



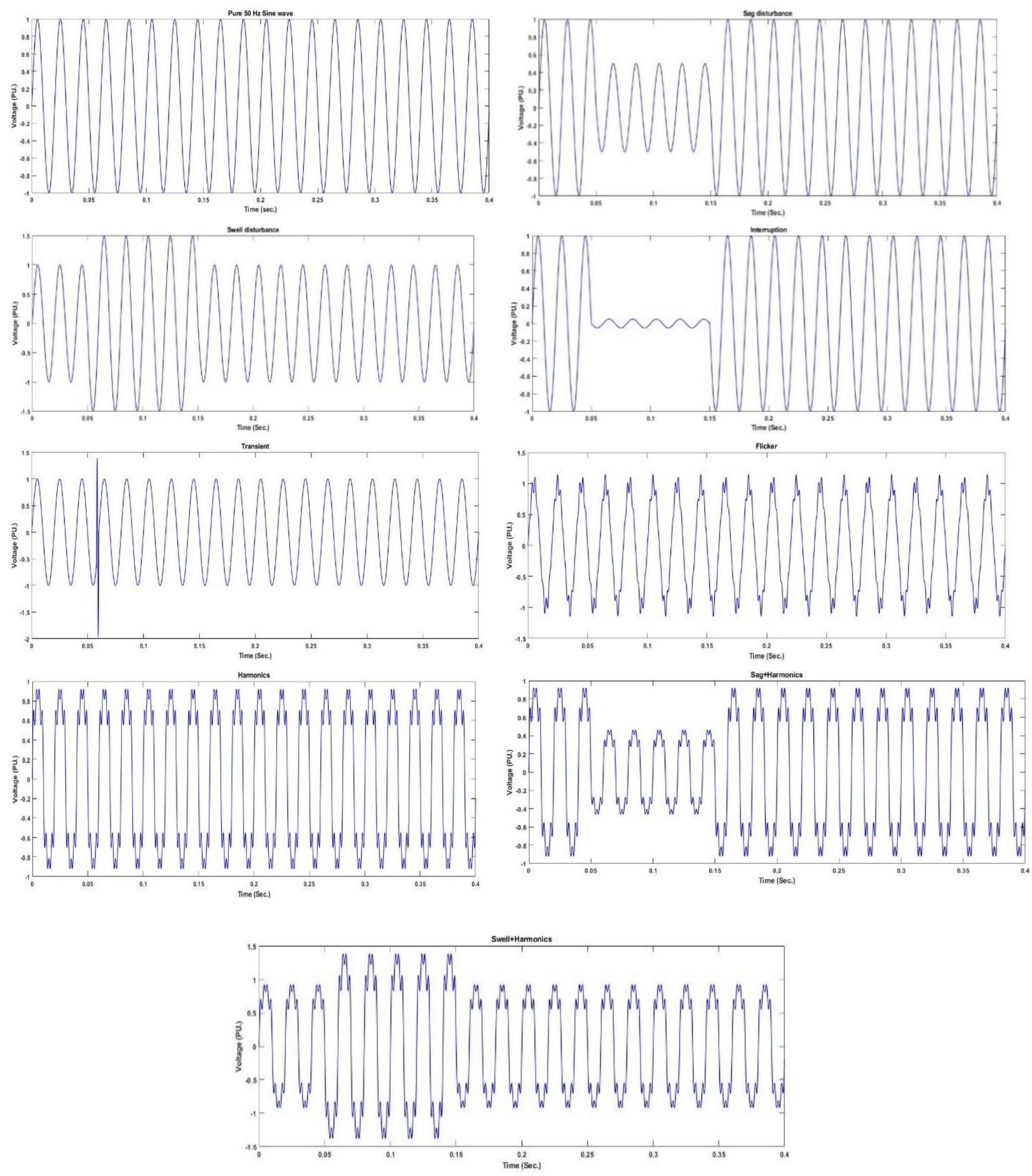

Figure 1. Power Quality disturbances waveforms

\section{ELECTRICAL POWER DISTRIBUTION MODEL}

Model of electric power distribution and Its Simulink diagram as shown in Figure 2. 


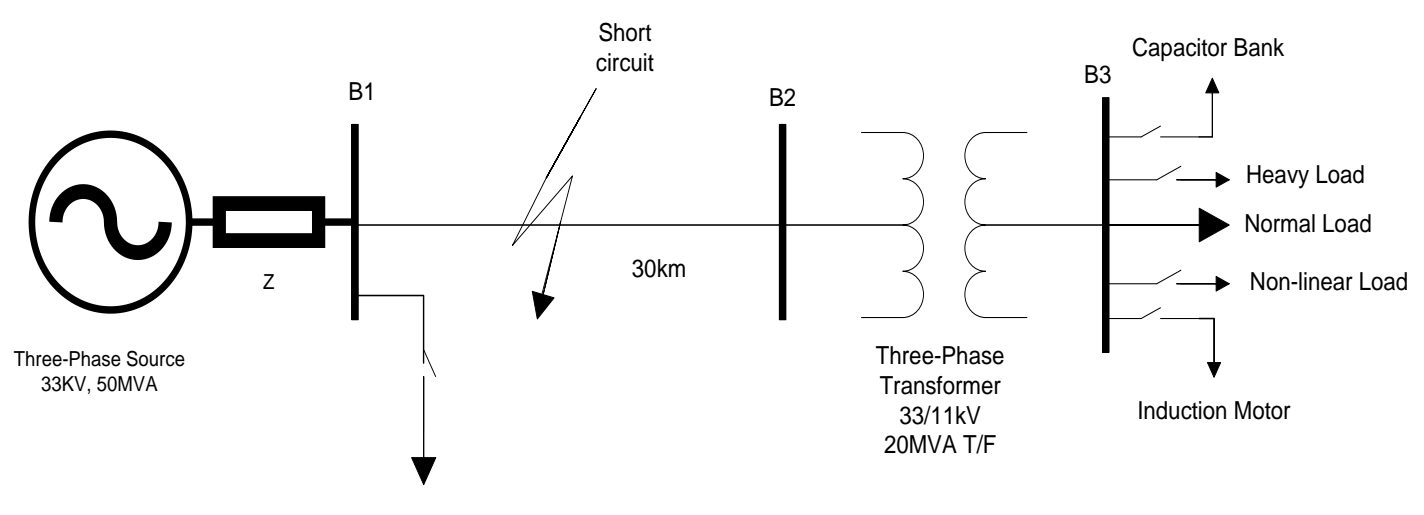

Capacitor Bank

(a)

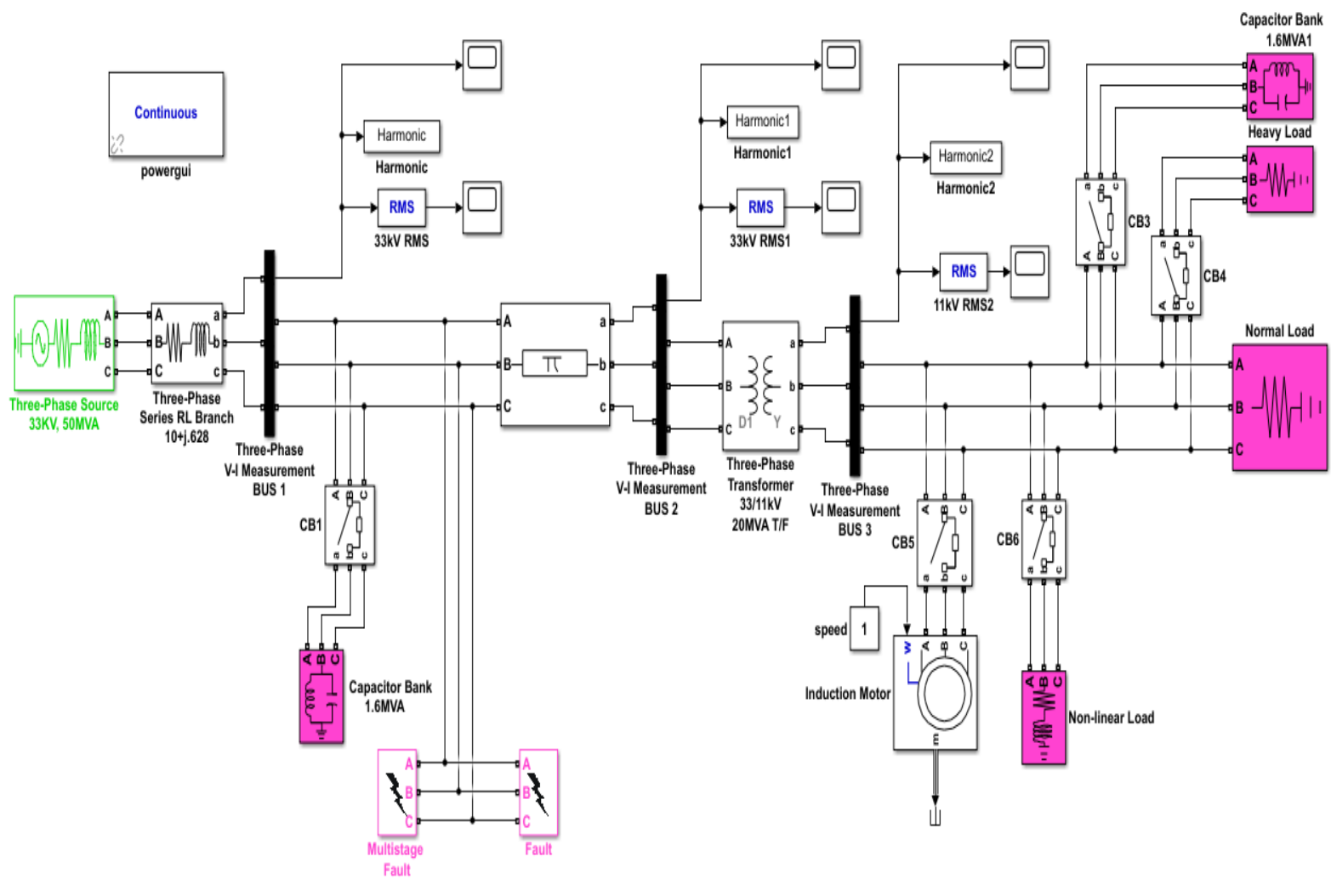

(b)

Figure 2. (a) Model of electric power distribution (b) Its Simulink diagram

\section{MODEL OF ELECTRIC POWER DISTRIBUTION}

In model of the electrical energy distribution structure happen simulated of power quality disturbances as set in Figure 2(a). The version consists of 33KV 50HZ, 50MVA generator with series RL branch(10+j.628), a delta/star step down transformer of 33/11KV 3-phase source block provide via, an impedance $30 \mathrm{Km}$ distribution line, a normal load and transformer be a delta/star step- down, 20MVA components an energy to usual (RL load, 1MVA) and non-linear (authority rectifier, 150V) load on the factor of commonplace coupling i.e., bus 3. The following loads are connected to the bus 3 capacitor bank, heavy load, normal load, induction motor and non-linear load each of which enters at a given time. The time of each case differs from the one controlled by a three-phase circuit breaker. The test version for distribution gadget is simulated into SimPowerSystems and Simulink Blockset for MATLAB that is proven into Figure 2 (b). The version is usage to take a look at numerous power quality disturbances in strength system because of capacitor bank, heavy load, normal load, non-linear load, induction motor and system faults. 


\section{RESULTS OF THE SIMULATION}

The MATLAB/Simulink software helps to receive the power quality disturbances waveforms by way of the usage of mathematical models as long as energy apportionment select model. Effect of fault on the Electrical power distribution model as shown in Figure 3.
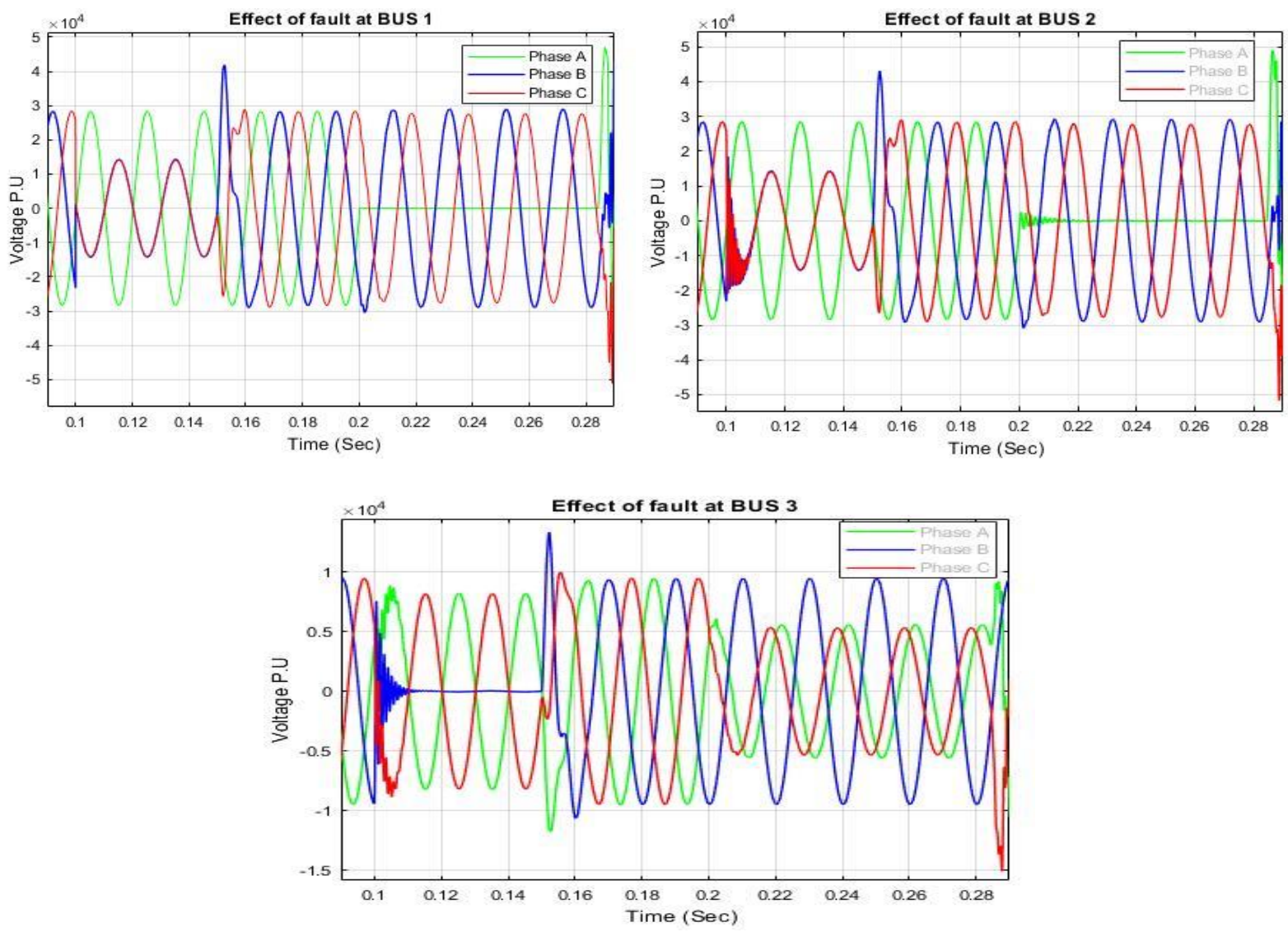

Figure 3. Effect of fault on the Electrical power distribution model

The capacitor bank energizing version advanced at Simulink is proven at Figure 2 (b). In the power system is amendment for power factor it's far utilize for simulate voltage temporary resulting from capacitor banking energizing. In the bus 1 additionally prepared with a capacitor bank (1.6MVA). In the general design two will be entered from capacitor bank, the capacitor bank 1 occurred at (0.4-0.45) sec. and capacitor bank 2 occurred at (0.6-0.68) sec with two fault as shown in Figure 4, the fault 1 happened at (0.1-0.14) sec which happen fault between phase $\mathrm{A}$ and phase $\mathrm{B}$ and the fault 2 happened $(0.2-0.28) \mathrm{sec}$ which happen fault between all phase as shown in Figure 3. The voltage brief value decreases because it proliferates upriver towards the $33 \mathrm{kV}$ bus feeder. The volume for the capacitor bank determines the voltage temporary frequency. The rate for the surge undoing down its vibration is relying on the dimensions for the load. A bigger load offers inflated damping factor, for that reason leading from quicker agreement for transient oscillation. In Figure 5 the induction motor in Simulink model beginning in the time a certain between (0.3-0.34) sec, which dominates on two phase (A and C) and it will work with $200 \mathrm{HP}$. 

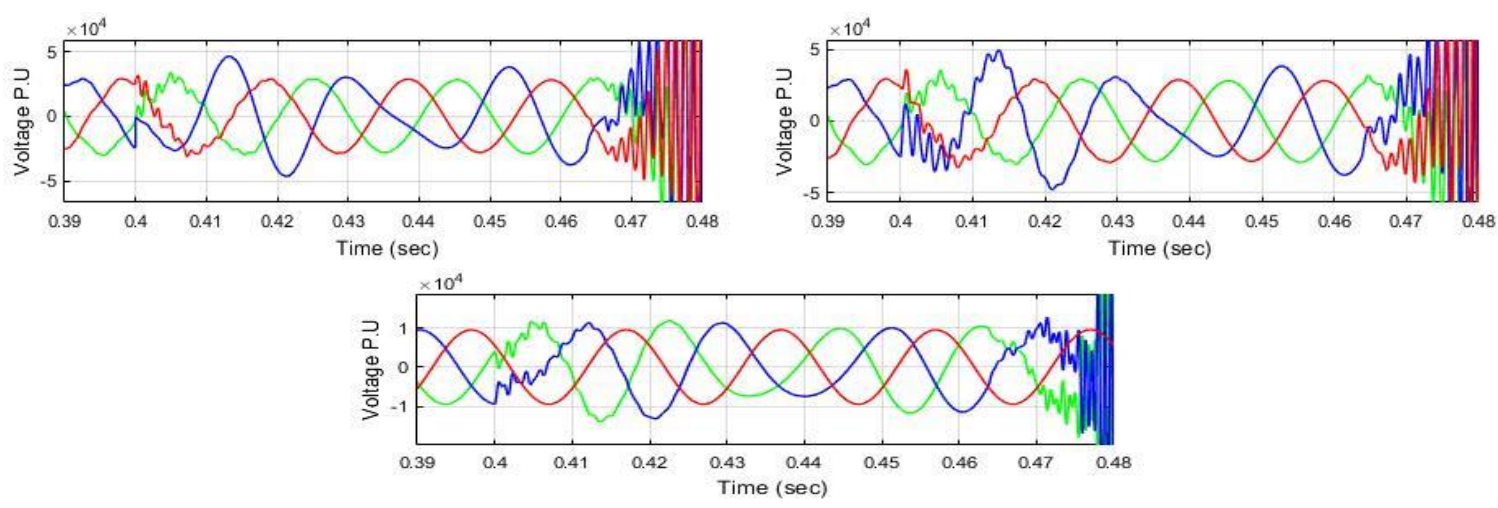

(a)
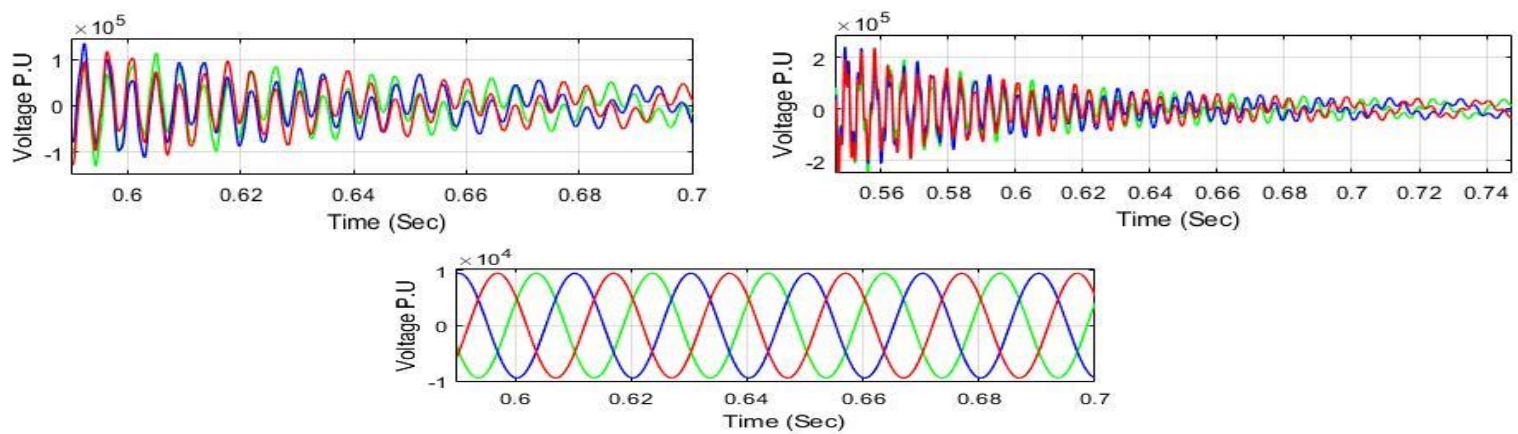

(b)

Figure 4. (a) Simulation the capacitor bank energizing 1 of Voltage Transient (b) It's for cause capacitor bank energizing 2
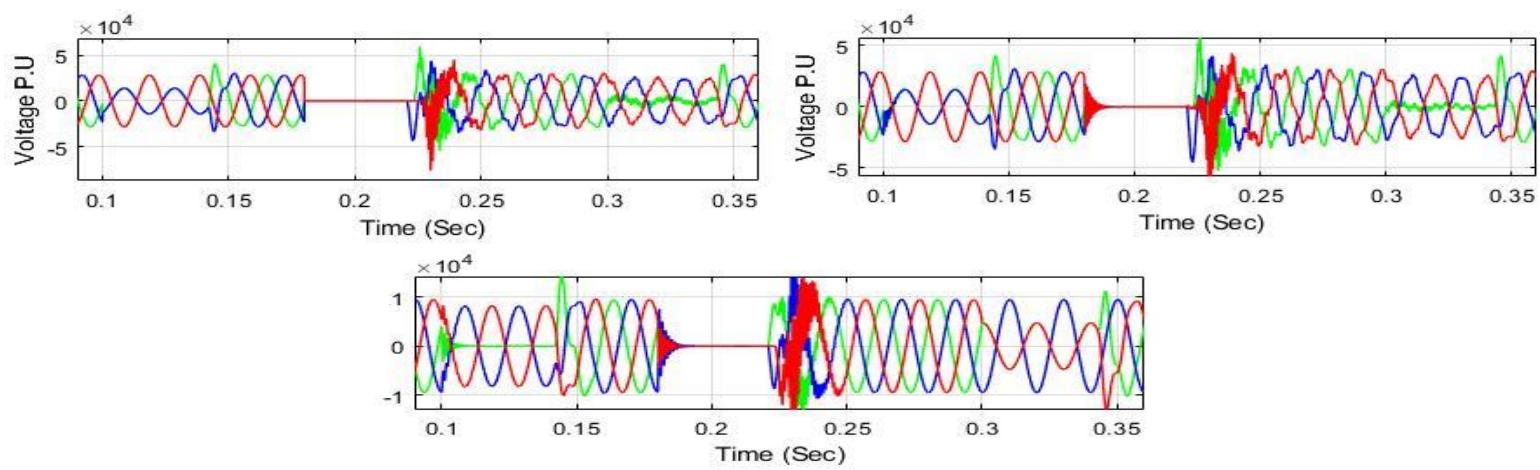

(a)
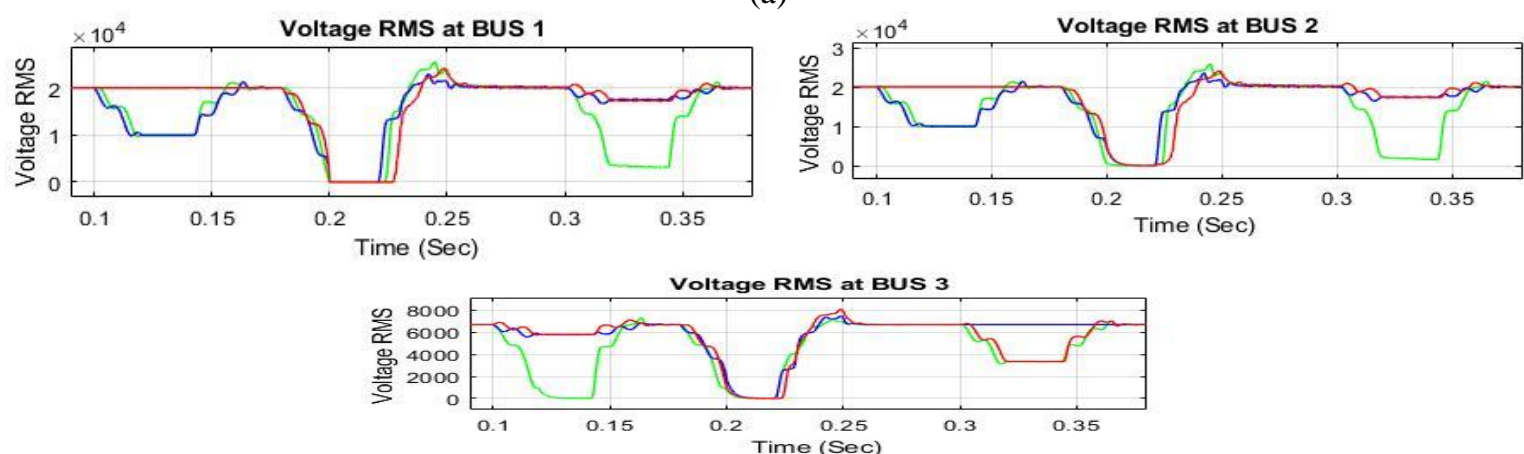

(b)

Figure 5. (a)Simulation for voltage sag because of beginning of induction motor in $\mathrm{Pu}(\mathrm{b})$ Simulation for voltage sag because of beginning of induction motor in RMS 
It begins design may be usage for simulate voltage sag due to induction motor beginning, voltage sag effected via the aid of induction device load in addition to multistage fault. The voltage sag size grow because it reproduces upstream across the $33 \mathrm{kV}$ feeder wherein the voltage sag turns into slender. The sag value for the induction motor voltage sag is resolute through the ability grade for it. The better the induction motor ability score, decrease the sag value. Simulation of Three Phase Non Linear Load and heavy load with fault (a) at Voltage P.U (b) at Voltage RMS as shown in Figure 6.
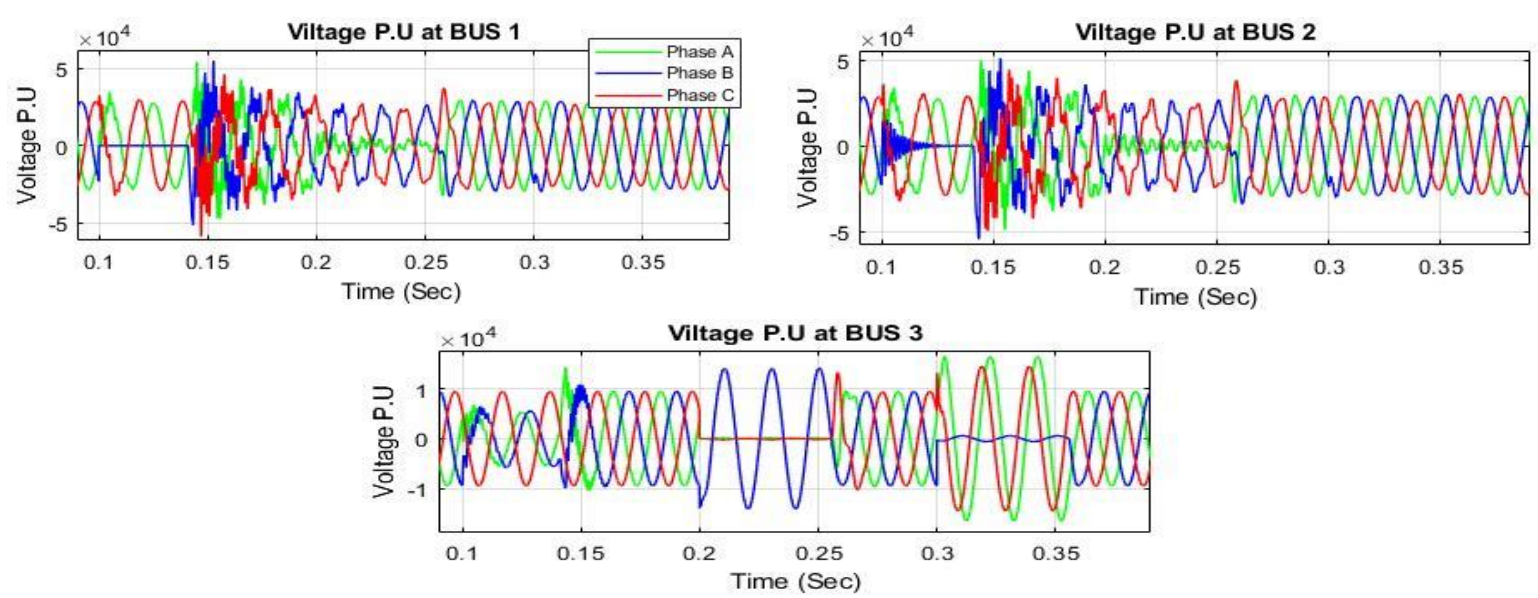

(a)
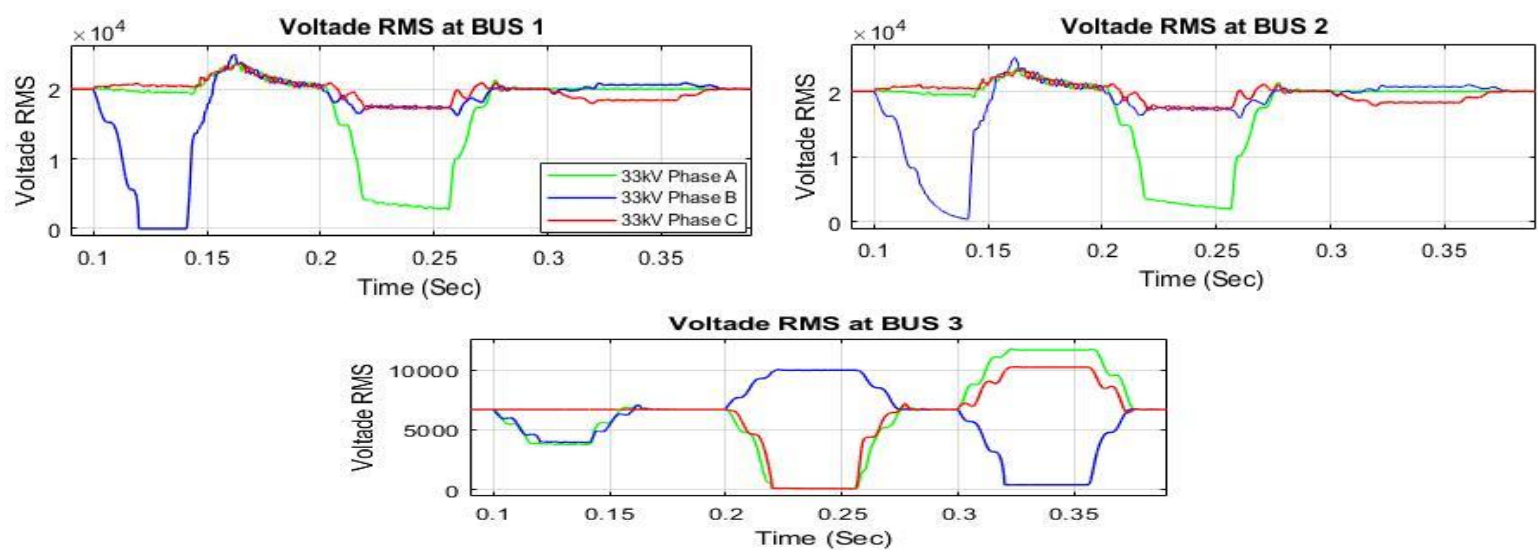

(b)

Figure 6. Simulation of Three Phase Non Linear Load and heavy load with fault (a) at Voltage P.U (b) at Voltage RMS

In Figure 6 (a), two cases on the system represent each instance on a segment with only one fault and each situation get in a given time, the fault come in from (0.1-0.14) seconds and is on phase B with ground. The steady-state distortions happen result the non-linear load to such same harmonics. The entry time to the non-linear load from (0.2-0.25) sec (20 cycles), be authoritarian on phase A and B, the effects appeared as in Figure 6 (a) in all cases. These species of energy quality distribution are swell, interference and voltage sag which formed within the energy allocation deliver gadget through entering a heavy load and brief circuit faults.

\section{DISCUSSION}

The signals of power quality disturbances can create by using MATLAB/Simulink software program. The disturbances may be produced with unique magnitudes in in keeping with unit, time intervals, and immediate on waveform. By means of connecting numerous energy system building block inside the simulation surroundings the power system model is created to simulate the energy quality event is ability the simulation technique presents researchers. Simulation technicality offer researchers the ability to produce 
energy system version into simulate energy quality disturbances via collect numerous energy system. It grants an insight to help PQ event increase and conduct in the simulated energy system model. The determination for simulation method its dependency in the ability for the selection simulation.

\section{CONCLUSION}

This paper offers in two ways by Simulink model and simulation (mathematical models) them have the ability to simulate the event distribution of power quality level inclusive voltage swell, voltage sag, harmonic, voltage notch and transient. This Simulink mode integrated avail as essential version for constructing greater complex to simulation of power quality event. Tis model is too beneficial to simulate numerous energy waveforms for analysis algorithm private power quality.

\section{REFERENCES}

[1] Mohd Izhwan Muhamad, Norman Mariun, Mohd Amran Mohd Radzi, "The Effects of Power Quality to The Industries", IEEE 5th Student Conference on Research and Development, SCOReD., 2007.

[2] D Danalakshmi, Srinivas Bugata, Kohila J, "A control strategy on power quality improvement in consumer side using custom power device", Indonesian Journal of Electrical Engineering and Computer Science (IJEECS), Vol. 15, No. 1, July 2019, pp. 80-87

[3] Pankaj Gakhar," A Novel Control Strategy for Power Quality Improvement in Grid-Connected Solar Photovoltaic System," Indonesian Journal of Electrical Engineering and Computer Science (IJEECS), Vol 15, No 3: September 2019.

[4] Khokhar, S., Zin, A., Mokhtar, A. and Ismail, N. (2014). "MATLAB/Simulink based modeling and simulation of power quality disturbances". 2014 IEEE Conference on Energy Conversion (CENCON).

[5] Alex McEachern, "A Free Simulator Program for Teaching Power Quality Concepts", 9th International Conference Electrical Power Quality and Utilisation, Oct 2007.

[6] D Danalakshmi, Srinivas Bugata, Kohila J," A control strategy on power quality improvement in consumer side using custom power device," Indonesian Journal of Electrical Engineering and Computer Science (IJEECS), Vol. 15, No. 1, July 2019, pp. 80-87.

[7] Lokendra Bam, Ward Jewell, "Review: Power System Analysis Software Tools", IEEE PES General Meeting, Vol. 1, pp. 139-144, Jun 2005.

[8] Miklos Danyek, Peter Handl, David Raisz, "Comparison of Simulation Tools ATP-EMTP and MATLAB-Simulink for Time Domain Power System Transient Studies".

[9] Nita R.Patne, Krishnarao L.Thakre, "Stochastic Estimation of voltage Sag Due to Faults in the Power System by Using PSCAD/EMTDC Software as a Tool for Simulation", Journal of Electrical Power Quality and Utilisation, Vol. 13, No. 2, pp. 59-63, 2007.

[10] Jose Maria Carvalho Filho, Roberto Chouhy Leborgne, Jose Policarpo G. de Abreu, Eder G.C. Novaes, Math H.J. Bollen, "Validation of Voltage Sag Simulation Tools: ATP and Short Circuit Calculation Versus Field Measurements", IEEE Transactions on Power Delivery, Vol. 23, No. 3, pp. 1472-1480, July 2008.

[11] Hadi Saadat, "Power System Analysis", 2nd Edition, ISBN 007-123955-3, McGraw Hill, 2004.

[12] M. Ntombela, K.K. Kaberere, K.A. Folly, A.I. Petroianu, "An Investigation into the Capabilities of MATLAB Power System Toolbox for Small Signal Stability Analysis in Power Systems", IEEE PES Conference and Exposition, July 2005.

[13] F. Milano, "An Open Source Power System Analysis Toolbox", IEEE Transaction on Power Systems, Vol. 20, No. 3, pp. 1199-1206, Aug 2005.

[14] L. Vanfretti, F.Milano, "Application of the PSAT, an Open Source Software for Educational and Research Purposes”, IEEE PES General Meeting, Jun 2007.

[15] Gilbert Sybille, Hoang Le-Huy, "Digital Simulation of Power Systems and Power Electronics using the MATLAB/Simulink Power System Blockset”, IEEE PES Winter Meeting, Vol. 4, pp.2973-2981, Jan 2000.

[16] Gilbert Sybille, Patrice Brunelle, Hoang Le-Huy, Louis A. Dessaint, Kamal Al-Haddad, "Theory and Applications of Power System Blockset, A MATLAB/Simulink-Based Simulation Tool for Power Systems", IEEE PES Winter Meeting, Vol. 1, pp. 774-779, Jan 2000.

[17] Louis-A. Dessaint, Kamal Al-Haddad, Hoang Le-Huy, Gilbert Sybille, Patrice Brunelle, "A Power System Simulation Tool Based on Simulink", IEEE Transactions on Industrial Electronics, Vol. 46, No. 6, pp. 1252-1254, Dec 1999.

[18] Karl Schoder, Amer Hasanovic, Ali Feliachi, Azra Hasanovic, "PAT: A Power Analysis Toolbox for MATLAB/Simulink", IEEE Transactions on Power Systems, Vol. 18, No. 1, pp. 42-47, Feb 2003.

[19] R. C. Dugan, M. F. McGranaghan, and H. W. Beaty, Electrical power systems quality vol. 2: McGraw-Hill New York, 1996.

[20] M. H. Bollen, Understanding power quality problems vol. 3: IEEE press New York, 2000. 


\section{BIOGRAPHIES OF AUTHOR}

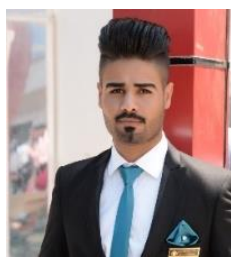

Ahmed Salam Hussein Al-Jumaili is student MSC with Electrical Power Engineering Techniques Department at Electrical Engineering Technical college, Middle Technical University. He received the B.S. degrees from the University of Al-Ma'mun, Iraq, Baghdad.

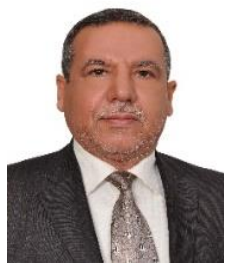

Majli Nema Hawas is presently Assistant Professor with Electrical Power Engineering Techniques Department at Electrical Engineering Technical college, Middle Technical University. He received the B.S., M.S and Ph.D. degrees from the university of Technology, Iraq, Baghdad. 